\title{
Prácticas represivas de vigilancia y hostigamiento sobre sobrevivientes de los centros clandestinos de detención en Bahía Blanca, Argentina (1976-1979)
}

\author{
Repressive practices of surveillance and harassment on survivors of \\ clandestine detention centers in Bahia Blanca, Argentina (1976-1979)
}

\author{
Cristian Rama*
}

\begin{abstract}
Resumen: Luego de salir con vida de los centros clandestinos de detención (CCD) que dispuso la última dictadura militar en Argentina (1976-1983), algunos de los sobrevivientes continuaron siendo objeto de prácticas de vigilancia y de hostigamiento por parte del aparato represor. Desde un estudio situado en Bahía Blanca, en este artículo se reconstruirán estas acciones, sus objetivos y las formas en que las víctimas, en un contexto de desestructuración más amplio, las experimentaron.
\end{abstract}

Palabras clave: sobrevivientes- vigilancia- hostigamiento- Bahía Blanca- dictadura militarcentros clandestinos de detención

\begin{abstract}
After coming out alive from clandestine detention centers (CDCs) established by the last military dictatorship in Argentina (1976-1983), some survivors continued being kept under surveillance and subject to harassment by the repressive apparatus. From a studio located in Bahía Blanca, this paper will reconstruct those actions, their objectives, and the way in which the victims, in a context of wider destructuring, experienced it.
\end{abstract}

Key words: Survivors- surveillance- harassment- Bahía Blanca- military dictatorshipclandestine detention centers

Recibido: 12 septiembre 2017

Aceptado: 9 noviembre 2017

\footnotetext{
* Argentino. Licenciado y Profesor en Historia por la Facultad de Filosofía y Letras (FFyL) de la Universidad de Buenos Aires (UBA). Actualmente realizando un Doctorado en la misma institución, con una beca cofinanciada entre la Universidad Nacional de Avellaneda (UNDAV) y el Consejo Nacional de Investigaciones Científicas y Tecnológicas (CONICET). cristiannrama@gmail.com
} 


\section{Introducción}

Los centros clandestinos de detención (CCD) fueron uno de los dispositivos represivos utilizados durante la última dictadura militar en Argentina ('76-'83). Resultaron centrales sobre todo durante los primeros tres años del periodo. En esos espacios, en general, las personas detenidas-desaparecidas recibieron distintas formas de ataques a la subjetividad debido a los métodos de tortura, de humillación y a las condiciones mismas de la detención ${ }^{1}$. Su carácter sistemático ha sido denunciado ante diversos organismos e instituciones por el amplio arco de organizaciones de derechos humanos y políticas desde tiempos dictatoriales, así como también lo hicieron distintos investigadores de las ciencias sociales. Sin embargo, menos abordado ha sido el carácter también sistemático de la "producción de sobrevivientes"2 y en este sentido, las problemáticas que estas personas han experimentado luego de haber sido liberados.

Al salir de los centros clandestinos de detención (CCD), los sobrevivientes vivieron lo que denomino proceso de reaparición, temática central de la tesis doctoral que actualmente desarrollo. Con este concepto intento pensar cuestiones inscriptas a partir de la salida, siempre ligadas a las experiencias previas. Dados los niveles de la represión que accionó el gobierno de facto en el contexto de sus desapariciones y luego en el de sus reapariciones, estas personas debieron afrontar tanto los efectos que llevaban en sus cuerpos y en sus psiquis, como también los que experimentaron los distintos sectores sociales con los que se fueron re-vinculando (familia, vecindad, amigos, compañeros de espacios de sociabilidad, de militancia política, de trabajo, etc.). Durante este proceso, ciertos sobrevivientes padecieron el hostigamiento de miembros de las Fuerzas Armadas y de seguridad, incluidos en este accionar algunos de sus propios victimarios.

En este artículo se pretenderá probar que en esas prácticas los represores persiguieron ciertos objetivos. Por un lado, en algunos casos, la obtención de información con el fin de seguir produciendo detenciones. Pero a su vez, a través de la exhibición del control, buscaron continuar amenazando e inhibiendo el desarrollo de determinados aspectos de la vida de los sobrevivientes. De esta manera, la continuidad del terror debía abonar el aislamiento de las víctimas, su atomización y en algunos casos su desarticulación política, lo que puede pensarse como un continuum con el proceso de destrucción de la subjetividad iniciado en los CCD.

\footnotetext{
${ }^{1}$ Diversos autores han concluido que uno de los principales objetivos de los CCD fue la destrucción de la subjetividad de los detenidos desaparecidos, por nombrar algunos: Eduardo Luis Duhalde, El Estado Terrorista argentino: 15 años después, Buenos Aires, Eudeba, 1999; Diana Kordon, Lucila Edelman, Darío Lagos, Raquel Bozzolo, Elena Nicoletti, Daniela Siaky, Ester Kandel, Marta Hoste, Osvaldo Bonano, Daniel Kersner, Efectos psicológicos de la represión política, Buenos Aires, Sudamericana, 1986; Pilar Calveiro, Poder y desaparición: Los campos de concentración en Argentina, Buenos Aires, Ed. Colihue, 2008 [1998].

2 Julieta Lampasona, "Desaparición forzada en Argentina: entre la desaparición y la sobrevida. O sobre la 'regla' y la 'excepción' en el despliegue de la tecnología de poder genocida”, La Plata, Aletheia, volumen 3 , número 6, julio 2013.
} 
Si bien estas prácticas no fueron padecidas por la gran mayoría de los sobrevivientes, sí las llevaron a por represores de varios $\mathrm{CCD}^{3}$. De todas maneras, pueden reconocerse matices en las experiencias vinculados a los contextos en los que comenzó la reaparición, la temporalidad, el territorio y ambiente en el que continuaron sus vidas, las trayectorias de las víctimas, cuán afectados estaban por el proceso vivido y particularidades relacionadas al funcionamiento del aparato represivo que padecieron.

Existieron en Bahía Blanca ciertas características "locales"4 destacables que tuvieron influencia en el proceso de reaparición. Por ejemplo, el apoyo a la dictadura y en algunos casos la colaboración de sectores de influencia de la sociedad civil, como el ejercido desde el monopolio comunicacional de la familia Massot, o el de sectores religiosos, empresarios, y el de miembros del poder judicial. Pero, sobre todo, este trabajo se interesa por abordar un aspecto que se considera central: la importante cantidad de instituciones militares y de seguridad interna en relación al número de ciudadanos, muchas para una ciudad mediana; fuerzas con larga tradición y atracción en una parte de la sociedad, ya fuera como fuente de trabajo y/o espacio de pertenencia.

Esta presencia de las instituciones produjo un significativo accionar de vigilancia sobre sectores de la población. La mayor parte de los casos en las causas judiciales tramitadas desde mediados de la década del dos mil, fueron presentados con registros de alguno de los organismos de inteligencia, en particular de la DIPBA (Dirección de Inteligencia de la Policía de la Provincia de Buenos Aires) y del SIPNA (Servicio de Inteligencia de la Prefectura Naval Argentina) ${ }^{5}$. En los casos de sobrevivientes, más del $74 \%$ figuran en ellos 6 , quedando expuesto el acopio de información posterior al paso por los CCD.

\footnotetext{
${ }^{3}$ Por ejemplo, se produjeron este tipo de acciones sobre sobrevivientes del llamado Circuito Atlético-BancoOlimpo, en el Circuito Camps, en el Vesubio y en la ESMA. Cristian Rama, Sobreviviendo: Experiencias en el marco del proceso de aparición de sobrevivientes de los centros clandestinos de detención de la última dictadura militar (Tesis de Licenciatura en Historia, FFyL, UBA, 2015.

${ }^{4}$ Silvina Jensen, "Diálogos entre la Historia Local y la Historia Reciente en Argentina. Bahía Blanca durante la última dictadura militar", en Rey Tristán, Eduardo; Calvo González, Patricia. XIV Encuentro de Latinoamericanistas Españoles: congreso internacional, Santiago de Compostela, Spain, Universidad de Santiago de Compostela, Centro Interdisciplinario de Estudios Americanistas Gumersindo Busto; Consejo Español de Estudios Iberoamericanos, Sep. 2010, pp.1426-1447. En los últimos años las investigaciones sobre la Historia Reciente en Bahía Blanca han tenido un notable crecimiento. Distintas historiadoras vienen analizando desde "lo local" una serie heterogénea de problemáticas que han complejizado las formas de pensar el pasado reciente en otras escalas. Por ejemplo, los trabajos de Ana Belén Zapata, Virginia Dominella, Lorena Montero, Ana Inés Seitz, Ana Vidal y María Julia Giménez, algunos serán citados a lo largo del artículo.

${ }^{5}$ Sobre la historia, el funcionamiento y la lógica burocrática de la DIPBA, ver: Patricia Funes, "Medio siglo de represión. El Archivo de la Dirección de Inteligencia de la Policía de la Provincia de Buenos Aires". La Plata, Revista Puentes (11), 2004; Emmanuel Nicolás Kahan, “¿Qué represión, qué memoria? El archivo de la represión de la DIPBA: Problemas y perspectivas", Question, vol. $\mathrm{N}^{\mathrm{o}}$ 1, $\mathrm{N}^{\mathrm{o}}$. 16, 2010, 1-10. http://perio.unlp.edu.ar/ojs/index.php/question/article/view/459; Débora D’Antonio, Vigilancia, control social y agencia política del activismo por los derechos humanos ante la llegada de la Comisión Interamericana de Derechos Humanos (Argentina, 1979), Izquierdas, 32, marzo 2017: 184-202

${ }^{6}$ Este porcentaje es producto de un trabajo de relevamiento realizado por el autor en el archivo de ex DIPBA, actualmente a cargo de la Comisión Provincial por la Memoria (CPM). La tarea se estructuró en los listados
} 
La percepción o aseveración de los sobrevivientes con respecto a esta vigilancia varió dependiendo de muchos factores. Algunos no le dieron relevancia, sobre todo en aquellos casos en los que contaban con experiencias represivas previas. Como ha abordado en diversos trabajos la historiadora Ana Belén Zapata, el análisis de la relación entre vigilantes y vigilados en una ciudad mediana como ésta, permite repensar la idea de una vigilancia omnisciente y no resistida. El cúmulo de situaciones represivas vividas, sobre todo por referentes gremiales y políticos, permitió también acciones resistentes ${ }^{7}$. No obstante, no fueron pocos los casos en los que los efectos psicosociales del paso por el CCD produjeron dificultades en la reestructuración de sus vidas y en este sentido, las sensaciones de amenaza por volver a ser secuestrados (o asesinados) tuvieron consecuencias en el proceso. De esta manera, en un contexto de desestructuración más amplio, el sentir esa posible presencia de las fuerzas haciendo vigilancia pudo resultar amenazante. En esto, entonces, resulta clave pensar el estado de la subjetividad de las víctimas y el de conservación o ruptura de los vínculos.

Por otro lado, además de que para algunos esas sensaciones pudieron funcionar como inhibidoras, otros sobrevivientes padecieron situaciones de hostigamiento por parte del aparato represor. A diferencia de la inteligencia "tradicional", en estas prácticas los represores "clandestinos" buscaron una relativa exposición.

La idea del presente trabajo es analizar este tipo de acciones represivas, para pensar sus consecuencias en el proceso de reaparición. En la primera parte se desarrollarán, en forma breve, algunas de las características que adquirió la vigilancia durante los años de la última dictadura $^{8}$, para a su vez mostrar la continuidad de estas prácticas sobre las personas que atravesaron los distintos espacios de encierro. Luego, se abordarán las percepciones que algunos sobrevivientes tuvieron respecto del sentirse vigilados y su relación con el terror producido en los CCD. Finalmente, se hará hincapié en distintas formas de hostigamiento y las maneras en que las víctimas las enfrentaron.

El marco temporal tomado como referencia será el de la última dictadura militar en Argentina ("76-'83), pero sobre todo se hará hincapié en los primeros tres años, que es cuando ocurrió la mayor cantidad de casos de hostigamiento sobre sobrevivientes cara a cara. Esto no significa que luego no existieran situaciones de amenazas, de hecho, éstas continuaron también durante distintos contextos del periodo democrático abierto en diciembre del '83. En estos casos, se dieron, en general, previo a denuncias o a declaraciones de las víctimas en los juicios.

Gran parte de la documentación utilizada proviene de dos de las primeras causas judiciales llevadas adelante en Bahía Blanca luego de la nulidad de las leyes de Punto Final

de personas que fueron caso y que aparecen con documentación de inteligencia en los fundamentos de la sentencia de la Causa "Fracassi..." y en los alegatos de la Unidad Fiscal de Bahía Blanca en el marco de la Causa "Bayón...". Lo relevado permitió acceder a más del doble de registros de los que figuraban en las causas.

7 Ana Belén Zapata, "Perseguidos de larga data: vigilancia y represión en trabajadores ferroviarios. Bahía Blanca (1958-1976)", en Patricia Funes (dir.), Revolución, Dictadura y Democracia. Lógicas militantes y militares en la historia reciente de Argentina en América Latina, Buenos Aires, Imago Mundi, 2016, pp.142163.

${ }^{8}$ En futuros trabajos se abordará en forma más específica las características de esa vigilancia. 
y Obediencia Debida y del fin de los indultos9: "Bayón..." (V Cuerpo I), y "Fracassi..." (Armada $)^{10}$. Estas presentan la mayor cantidad de casos de desaparecidos, de asesinados y de detenidos liberados. También, se expondrán fragmentos de entrevistas personales con sobrevivientes de CCD de esa ciudad, realizadas entre los años 2015 y 2016.

\section{El marco local}

En el proceso de reaparición mucho tuvo que ver el grado de afectación del sobreviviente, pero también el del medio al que retornaría. En este sentido, es importante pensar en la dialéctica entre las condiciones subjetivas de la persona que salió con vida de esos espacios y las de la sociedad con la que re-establecería los vínculos, lo que denomino "re-vinculación".

De todas las características locales de Bahía Blanca nombradas en la introducción, todas muy importantes para pensar a la sociedad bahiense, me interesa entonces destacar una que resulta clave: la cantidad de instituciones represivas y su grado de inserción y acción en la sociedad. Como menciona la historiadora María Lorena Montero: "En la década del setenta, Bahía Blanca era un territorio sitiado por fuerzas militares que contaban con los recursos necesarios para diagramar y poner en ejecución un complejo y articulado plan represivo" "La presencia de las fuerzas militares y de seguridad fue grande si se la piensa en relación a la cantidad de población para la época de la dictadura (aproximadamente doscientas mil personas poblaban la ciudad). Funcionó allí la sede central del V Cuerpo del Ejército, que ejerció la responsabilidad primaria en la represión de

\footnotetext{
${ }^{99}$ La ley de Punto Final (23.493) fue promulgada el 24 de diciembre de 1986, implicó la caducidad de acciones penales para el juzgamiento de los crímenes cometidos por "desaparición forzada" durante la última dictadura. Luego de un plazo de sesenta días de promulgada, aquellos que no hubieran sido llamados a una "declaración indagatoria", que no estuvieran "prófugos" o en "rebeldía", no podrían ser juzgados. La Ley de Obediencia Debida (23.521) del 04 de junio de 1987, estableció una presunción por la que los delitos cometidos por personal de las fuerzas debajo del escalafón de Coronel debían quedar exentos de ser juzgados, ya que estos "obedecían órdenes superiores". Por último, los indultos fueron una serie de diez decretos promulgados por el entonces Presidente Carlos Menem entre fines de 1989 y de 1990, a través de los cuales se indultó a más de 1200 personas juzgadas o procesadas, entre ellos miembros de las juntas militares y líderes guerrilleros. Durante el año 1998 las leyes de Punto Final y de Obediencia Debida fueron derogadas, no obstante, recién serían declaradas nulas el 12 de agosto de 2003, ley 25.779.

${ }^{10} \mathrm{El}$ debate del juicio por la causa N $\mathrm{N}^{\circ} 982$ caratulada "BAYÓN, Juan Manuel y otros s/privación ilegal de la libertad agravada, reiterada, aplicación de tormentos reiterada, homicidio agravado, reiterado a Bombara, Daniel José y otros en área del Cuerpo Ejército V", fue llevado adelante entre los años 2011 y 2012, dictando sentencia sobre 17 represores ligados al área de influencia del V Cuerpo del Ejército. El del juicio por la causa 1.103 caratulada "FRACASSI, Eduardo René y otros por privación ilegal de la libertad agravada, reiterada, aplicación de tormentos reiterada, homicidio agravado reiterado a AGUILAR, Guillermo Aníbal y otros (Armada Argentina)", fue realizado entre el 2014 y 2015, condenando a 22 represores ligados a la zona de la Armada. Ambas sentencias y fundamentos están actualmente online. http://www.cij.gov.ar/sentencias.html

${ }^{11}$ María Lorena Montero, "El rol de la 'comunidad informativa' en la represión en Bahía Blanca (1975-1977): prácticas, acuerdos y disputas", en Gabriela Águila, Santiago Garaño y Pablo Scatizza (coordinadores), Represión estatal y violencia paraestatal en la historia reciente argentina: Nuevos abordajes a 40 años del golpe de Estado, La Plata, Universidad Nacional de La Plata. Facultad de Humanidades y Ciencias de la Educación, 2016.
} 
la denominada zona 5, que abarcó toda la Patagonia. La ciudad junto a las linderas y algunas cercanas de Río Negro pertenecieron a la sub-zona 5-1, con sede en el Batallón de Comunicaciones 181. A su vez, la Armada, una institución con larga tradición en esa región, coordinó la represión con el Ejército dentro de sus propias áreas de acción. Si a ello se le suma la Prefectura, la Gendarmería, la Policía Federal, la Policía de la Provincia de Buenos Aires, los muy activos servicios de inteligencia de cada fuerza (que a su vez funcionaban en la llamada "comunidad informativa") ${ }^{12}$ y la Unidad Penitenciaria $\mathrm{N}^{\mathrm{o}} 4 \mathrm{de}$ Villa Floresta, se puede dimensionar la amplitud de la presencia de estas instituciones. En los alegatos que presentó la Unidad Fiscal durante el Juicio por la Causa "Bayón...", el Fiscal Abel Córdoba, decía:

Esa era la dimensión de Bahía Blanca, es decir que tenemos una desproporcionada estructura militar, respecto de la dimensión de la sociedad civil, esto, en principio, no debería ser un dato relevante, si es que los cañones de ese ejército no apuntaran hacia las calles de la ciudad, hacia las personas que vivían acá"13.

El grueso de la represión se llevó a cabo durante los años ' 76 y ‘77, aunque también hubo desapariciones en el ' $78^{14}$. De todas maneras, como a nivel nacional, el proceso represivo sobre las distintas organizaciones y referentes políticos tuvo continuidades ${ }^{15}$ de largo, mediano y corto plazo. Los dos años previos al golpe de Estado del 24 de marzo del '76 estuvieron marcados por el accionar de sectores paraestatales ligados a la Triple A, y por la puesta en marcha de distintas leyes y decretos impulsados desde el Poder Ejecutivo Nacional para combatir a la denominada "subversión", que fueron los que sentaron las bases normativas donde se estructuraría la organización de las fuerzas represivas de la dictadura $^{16}$. En este sentido, la lógica del dispositivo $\mathrm{CCD}^{17}$ también comenzó antes del

\footnotetext{
12 Idem.

${ }^{13}$ Unidad Fiscal de Bahía Blanca, "5 Contexto local", Alegato de la Unidad Fiscal en el primer juicio a represores en Bahía Blanca, Bahía Blanca, Agosto de 2012. Transcripto en el Blog Bahía Gris: http://bahiagris. blogspot.com.ar/2012/08/alegato-de-fiscalia-5-contexto-local.html

${ }^{14}$ Los principales CCD que funcionaron en la sub-zona 5-1 durante el periodo en cuestión, fueron: "la Escuelita" (que abarcó varias edificaciones) y el Batallón de comunicaciones 181, dentro de terrenos del V Cuerpo; y el "vagón de madera", en Cuatrerismo. En la zona y áreas de la Armada en la región: el Buque Ara 9 de Julio, la VII Batería y el Puesto 1, en la Base Naval Puerto Belgrano de Punta Alta; y dependencias de Prefectura de Bahía Blanca y comisarías locales.

${ }^{15}$ Marina Franco, "Pensar la violencia estatal en la Argentina del siglo XX", Buenos Aires, Lucha Armada en la Argentina, Año 8, Anuario 2012, pp. 20-31.

${ }^{16}$ Un análisis de la articulación entre los niveles nacional y local durante la etapa represiva previa al Golpe de Estado se puede ver en: Ana Belén Zapata, "Capítulo 20: Violencia estatal y paraestatal (1973-1976)", Andamios de experiencias: Conflictividad obrera, vigilancia y represión en Argentina. Bahía Blanca, 19661976, Tesis de posgrado, Universidad Nacional de La Plata, Facultad de Humanidades y Ciencias de la Educación, En Memoria Académica, 2014.

${ }^{17}$ Calveiro, óp., cit.
} 
golpe de Estado, siendo registrada la primera desaparición en Bahía Blanca en diciembre del ' $75^{18}$.

Existía mucha información sobre las organizaciones políticas, sindicales y de distintas personas de la comunidad, que los servicios de inteligencia venían procesando desde varios años atrás ${ }^{19}$. El rol de éstos fue crucial, excediendo a la actividad de fijación de "blancos". Participaron activamente en distintas tareas, inclusive algunos comandando la tortura dentro de los CCD, tanto en los del Ejército como en los de la Armada. Como menciona Montero, no sólo formaron parte del aparato represivo sino que ocuparon una posición clave dentro del mismo: "constituyeron la ligadura que selló sus distintos eslabones y le permitió desplegarse (en diferentes niveles) a lo largo del tiempo y del territorio" $^{20}$.

Las prácticas de inteligencia continuaron durante la dictadura y en años de democracia, observable en los distintos tipos de registros e informes de los servicios ${ }^{21}$. En ellos se refleja información con respecto a los sobrevivientes de los CCD: los procesos de legalizaciones, los traslados a unidades penitenciarias, las visitas recibidas en los penales, las "libertades vigiladas", el seguimiento posterior a la salida de los encierros y los pedidos de antecedentes; las denuncias en comisarías de las propias víctimas; las cesantías aplicadas sobre aquellos que trabajaban en espacios laborales intervenidos; y controles sobre los teléfonos. Lo hicieron, también, sobre las actividades de búsqueda de justicia por los crímenes de la dictadura en la zona, antes y después del retorno de la democracia del 10 de diciembre del '83. Por ejemplo, en el reconocimiento del CCD la "Escuelita" realizado por cinco de las víctimas que estuvieron allí detenidas-desaparecidas, en el marco de la investigación llevada a cabo por la CONADEP en el año ' $84^{22}$. En el mismo sentido, aparecen registradas durante estas etapas, personas que tuvieron participación política en alguna agrupación, manifestación o en elecciones.

A su vez, accionaron sobre familiares, sobre todo cuando realizaban las gestiones y averiguaciones por las desapariciones, se organizaban en el reclamo y en la denuncia, y en momentos de visitas a las cárceles.

\footnotetext{
${ }^{18}$ Uno de los primeros casos fue el de Daniel Bombara, militante de la Juventud Universitaria Católica, desaparecido el 15 de diciembre de 1975. Diego Martínez, "El primer desaparecido de Bahía”, Buenos Aires, Página/12, lunes 25 de marzo de 2013. https://www.pagina12.com.ar/diario/elpais/1-216541-2013-0325.html

${ }^{19}$ Algunos incluso desde fines de los ‘50. Ibídem, p. 346.

${ }^{20} \mathrm{La}$ autora analiza la estructura y el rol clave que tuvieron los distintos servicios de inteligencia durante el periodo '75-'77, tanto a nivel nacional como local. Desde esta última "escala", expone el funcionamiento de la llamada "comunidad informativa" y demuestra cómo las actividades de algunos miembros del personal de los servicios excedió el rol de señalar "blancos”. Montero, óp., cit., p. 387.

${ }^{21}$ La información fue registrada de distintas maneras por los servicios de inteligencia. Por ejemplo, tanto en la DIPBA como en el SIPNA, produjeron fichas individualizadas por persona, en la que figuran sus legajos. Pero también, los "vigilados" aparecen en informes zonales, como los realizados por la Prefectura Zona Atlántico Norte (PZAN). Estos fueron producidos por "factor" ("gremial”, "político", "económico", "subversivo", etc.), por localidad y grupos y en distintas periodizaciones (mensual, bimestral, trimestral, etc.). A su vez, el archivo cuenta con recortes periodísticos, panfletos, folletos o boletas electorales que producían las organizaciones, en las que podían aparecer las víctimas.

${ }^{22}$ La delegación local de la CONADEP funcionó desde fines de mayo a septiembre del ‘84.
} 
De los 54 casos de sobrevivientes que fueron presentados en el juicio por la causa "Bayón...", 41 aparecen mencionados en algún informe ${ }^{23}$. En la causa "Fracassi...", el número es similar: de los 48, 32 $2^{24}$. Si sumamos ambas causas, de 102 casos, 73 figuran en registros de alguno de los servicios de inteligencia, siendo las mismas víctimas o algún familiar los "vigilados", lo que daría más de un $74 \%$. Por otro, la documentación relevada por las investigaciones académicas y judiciales corresponde sólo al material que tuvo circulación y fue archivado en el SIPNA y en la DIPBA. Quizás la existencia de documentos sobre las actividades de inteligencia del Ejército o de la Marina podría complejizar aún más el panorama, ya que ambas instituciones tuvieron otro grado de responsabilidad en la represión ${ }^{25}$.

El accionar del aparato represivo continuó entonces sobre varios de los sobrevivientes durante el proceso de reaparición. Los datos que figuran en los archivos de inteligencia son una evidencia de esto. Pero además de la vigilancia efectiva, algunos, como producto de las persecuciones y sobre todo por el terror vivido en los CCD, experimentaron la sensación de seguir siendo vigilados, lo que pudo tener efectos en el desarrollo de la vida posterior a las detenciones.

\section{Vigilancia, terror y desestructuración}

La mayor parte de los testimonios y análisis realizados por sobrevivientes, reflejan que en la experiencia del CCD los represores buscaron desestructurarlos. En general, los relatos hacen mención a que dadas las condiciones de la detención, la tortura excedió a los métodos utilizados durante los interrogatorios, estuvo en forma subyacente en la $\operatorname{cotidianidad}^{26}$. Por eso, los que reaparecieron debieron llevar consigo las marcas físicas y psíquicas de esa experiencia, con efectos de corto, mediano y largo plazo.

El miedo debido a la posibilidad de volver a ser secuestrados o de que miembros de la familia fueran afectados por los grupos de tareas, funcionó para algunos como un

23 Tribunal Oral Subrogante en lo Criminal Federal de Bahía Blanca, Poder Judicial de la Nación. Fundamentos dictados en la causa $N^{\circ} 982$ caratulada "BAYÓN, Juan Manuel y otros s/privación ilegal de la libertad agravada, reiterada, aplicación de tormentos reiterada, homicidio agravado, reiterado a Bombara, Daniel José y otros en área del Cuerpo Ejército V”, Bahía Blanca, 06 de noviembre de 2012. http://www.cij.gov.ar/nota-10317-Lesa-humanidad--difunden-fallo-que-conden--en-Bah-a-Blanca-a-14acusados-a-prisi-n-perpetua.html

24 Tribunal Oral Subrogante en lo Criminal Federal de Bahía Blanca, Poder Judicial de la Nación. Fundamentos dictados en la causa 1.103 caratulada "FRACASSI, Eduardo René y otros por privación ilegal de la libertad agravada, reiterada, aplicación de tormentos reiterada, homicidio agravado reiterado a AGUILAR, Guillermo Aníbal y otros (Armada Argentina)”), Bahía Blanca, 25 de noviembre de 2015. http://www.cij.gov.ar/nota-20136-Lesa-humanidad--difunden-fallo-que-conden--a-los-22-acusados-en-unjuicio-oral-en-Bah-a-Blanca.html

${ }^{25}$ Montero, óp., cit., p. 391.

${ }^{26}$ Esto puede observar también en bibliografía producida por sobrevivientes. Calveiro, óp., cit.; Munu Actis, Cristina Aldini, Liliana Gardella, Miriam Lewin, Elisa Tokar, Ese infierno: Conversaciones de cinco mujeres sobrevivientes de la ESMA, Buenos Aires, Sudamericana, 2001; Jorge Federico Watts, Memoria del infierno: Relato testimonial de un sobreviviente del Centro Clandestino El Vesubio, Buenos Aires, Ed. Continental, 2009; Mario Villani, Fernando Reati, Desaparecido: Memorias de un cautiverio, Buenos Aires, Biblos, 2011. 
condicionante en la reaparición. Esto lo vivieron sobre todo aquellos que experimentaron procesos de aislamiento con respecto a lo que eran sus espacios de pertenencia, al haber salido en esos momentos en los que se dio con mayor intensidad la represión, años ' 76 , '77 y '78. Por un lado, fue clave el estado de la subjetividad luego de experimentar la violencia del CCD. Por otro, el que los ámbitos socio-políticos que solían frecuentar habían sido o estaban siendo afectados: instituciones públicas y gremios intervenidos, agrupaciones prohibidas, compañeros desaparecidos, muertos, presos, y exiliados.

La dificultad para rearmar este tipo de lazos es observable mayormente en la militancia de base de cuyas estructuras organizacionales poco o nada quedaba, como también en aquellos que no militaban orgánicamente. No significó esto que los dirigentes o referentes de las organizaciones corrieran mejor suerte, pero sí algunos habían tenido experiencias de vigilancia y padecido también distintos tipos de represión, con lo que pudieron estar mejor preparados. Además, podían contar con tejidos y relaciones para afrontar con mayores recursos el proceso de reaparición ${ }^{27}$.

Como se mencionó en la introducción, la historiadora Ana Belén Zapata hace hincapié en la larga duración de ciertas prácticas represivas y de vigilancia, sobre todo contra organizaciones de trabajadores. Su análisis de los ferroviarios, metalúrgicos, portuarios, gráficos y miembros del gremio de la construcción de Bahía Blanca ${ }^{28}$, permite repensar a la vigilancia de los servicios de inteligencia como algo omnisciente y no resistido. En este sentido, su idea es que por las características locales ya mencionadas (la cantidad de fuerzas armadas y de seguridad, el tipo de relaciones posibles en una ciudad mediana y la gran conflictividad de estos gremios), y las experiencias relacionadas a la represión, ya fueran vividas en forma personal o trasmitidas generacionalmente, les permitieron a los miembros de esos espacios contar con herramientas para generar respuestas a los avances de las fuerzas. En este sentido, también, resalta que la vigilancia podía ser visible, ya que, en varios casos, estos trabajadores conocían a aquellos que llevaban adelante esa función.

De todas maneras, para otros, la etapa represiva y lo vivido en los CCD generó un gran nivel de desestructuración, que se evidencia en muchas de las historias de aquellos que salieron con vida en este contexto mencionado, que manifiestan efectos de la represión tanto en lo subjetivo como en sus círculos sociales. El terror, en combinación con la falta de vínculos empáticos para elaborar lo recientemente vivido, y la desconfianza ${ }^{29}$ de algunos de los sectores con los que se vincularían (y la propia para con estos), produjo distintos niveles de aislamiento. Esto no significó una parálisis o que no hayan realizado acciones de

\footnotetext{
${ }^{27}$ Por ejemplo, los hermanos Bustos, referentes de la JP y de la UOCRA a nivel local, que habían vivido y trabajado políticamente en el barrio Villa Libre, mantuvieron redes de sociabilidad que hicieron que, al salir de las situaciones de encierro, fuera menos traumática la reestructuración social, económica y política. Entrevista personal con René, Bahía Blanca, 08 de marzo de 2016.

${ }^{28}$ Zapata, óp., cit., 2014.

${ }^{29}$ Para Daniel Feierstein, como efecto del terror: "La desconfianza resultó uno de los modos más eficaces de clausurar las relaciones de reciprocidad y solidaridad (...)". Daniel Feierstein, El genocidio como práctica social: entre el nazismo y la experiencia argentina, Buenos Aires, Fondo de Cultura Económica, 2007, p. 341.
} 
resistencia, pero sí que padecieron procesos en los que al menos por un tiempo, les fue difícil convivir con el miedo, como se verá en las siguientes historias.

Neli, que había militado en el Partido Comunista (PC) desde fines de los ' 60 y en los sindicatos de actores y bancarios, fue secuestrada a principios de agosto del ' 76 . Su detención en el CCD la "Escuelita"30 duró alrededor de un mes. El represor que estaba a cargo de los "interrogatorios", Santiago "el tío" Cruciani, la llevó personalmente hasta su domicilio al día siguiente de haberle comunicado la liberación. Llegó arrastrándose a su casa luego de que la bajaran del automóvil en el que la llevaron, estaba muy afectada, tanto física como psíquicamente por todo lo vivido durante el mes de cautiverio. Una de las formas en la que eso se manifestó fue en el miedo de que la volvieran a secuestrar o de que le pasara algo a sus hijos: "[Mis hijas] me preparaban la cama con ellas, pasaba la noche despierta. Me acostaba debajo de las ventanas por el terror que tenía, miedo por mis hijos, miedo por los milicos, terror" 31 .

Esta sensación de terror, asociada a la posibilidad de un nuevo secuestro, se puede observar en las historias de varios sobrevivientes que salieron durante ese periodo de la dictadura. Silvia ${ }^{32}$ por ejemplo, secuestrada el 24 de septiembre del ' 76 pero por la Marina, narró durante su testimonio en el juicio por la causa "Fracassi..."33, cómo se sentía luego de haber logrado llegar a su casa y cuánto había afectado la experiencia a su personalidad:

(...) al momento de salir tenía mucho miedo, siendo que yo no era una persona miedosa, porque andaba para todas partes sola, y nunca tuve miedo, pero ahora tenía un terror, sentía que me seguían, que había autos que me alumbraban, eso fue muy feo y a la noche también, iba a mi pieza y tenía miedo que entraran, eso me quedó como sensación horrible durante mucho tiempo (...).

De ser una persona independiente, que se juntaba con distintos grupos para hacer actividades, que se sentía interpelada y actuaba ante lo que consideraba injusto, ahora tenía terror, se sentía perseguida, vigilada. La sensación de seguimientos, de autos que alumbraban, ruidos de frenadas, la noche, la desconfianza para relacionarse, fueron cuestiones que podían ser de por sí coercitivas. Para aquellos que se sentían vulnerables, la posibilidad de volver a ser secuestrados era grande, y de ahí las condiciones para el terror.

Cabe agregar que en los testimonios, muchos de los sobrevivientes exponen que si bien las condiciones de cautiverio impedían tener una ubicación espacio temporal y certezas de quiénes los habían secuestrado, fueron haciéndose de indicios con los que

\footnotetext{
${ }^{30}$ El CCD la Escuelita, ubicado detrás del predio del V Cuerpo en el Camino de la Carrindanga, fue uno de los dispositivos de desaparición con mayor actividad en la zona.

${ }^{31}$ Entrevista personal con Nélida, Buenos Aires, septiembre del 2016.

32 Silvia era docente y administrativa en la UNS. Si bien no tenía militancia orgánica, simpatizaba con el peronismo y participaba con un grupo de artistas que pintaba murales. Estuvo secuestrada desde el 24 al 29 de septiembre de 1976. Padeció enfermedades emocionales al salir, presentaba un cuadro depresivo agudo. Según ella, tenía "sensación de muerte".

33 Testimonio de Silvia en el marco de la Causa "Fracassi...", T.O.F. N 1 Bahía Blanca, 9 de diciembre de 2014.
} 
generaron hipótesis al respecto ${ }^{34}$. De esta manera, el saber que tal o cuál institución había estado a cargo de esas acciones pudo estar en consonancia con esas sensaciones de vigilancia relatadas, más aún para aquellos casos que tenían certezas. A estas construcciones debe sumarse la particularidad mencionada, de ser la región de Bahía Blanca un lugar en el que los miembros de las fuerzas estaban insertos en la sociedad. En su testimonio durante el juicio, en 2015, Marta hizo referencia a lo que significaba para ella vivir cerca de sus victimarios:

Es el día de hoy que aún tengo temor, yo me fui de Bahía Blanca para que al lado mío no se sentara ninguna de esas personas que habían sido los causantes de haberme dado tanto dolor y castigo (...). Mis hermanas quedaron acá, mis padres fallecieron, y cuando me jubilé, lo primero que hice fue gestionar irme lejos (...). ${ }^{35}$

Marta era empleada de ENTEL, tenía 40 años en el momento de su secuestro. Estuvo detenida-desaparecida desde el 18 de noviembre al 30 de diciembre del ' 76 en el CCD "Baterías". Participaba en el gremio de la empresa. Luego del proceso de detención fue dejada cesante, pudiendo reincorporarse recién al año. Recuerda que estaba muy mal, que nunca pudo juntar a la familia para contarle en detalles lo sucedido y que lo que la salvó fue adoptar a una niña al tiempo de salir, pudiendo dedicarse a su crianza. Fue objeto de inteligencia a más de un año de su salida, al igual que una década después. En un informe producido en el ' 87 se habla de su participación en una marcha contra la impunidad de ese año. En el mismo está registrado que durante el '78 se había unido a una agrupación teatral de "tendencia izquierdista"36.

En esta historia se observa entonces esa sensación de que en Bahía Blanca podía estar compartiendo espacios con los que le habían "causado dolor". De hecho, es sintomático que decide irse a Misiones ${ }^{37}$ luego de las leyes de Punto Final y de Obediencia Debida, contexto en el que comenzaba un periodo de impunidad con respecto al juzgamiento por los crímenes del periodo dictatorial ${ }^{38}$. Pero, por otro lado, también se

\footnotetext{
34 Por ejemplo, en los CCD ligados a la Armada, son muchos los que describían los sonidos "a mar", el tiempo de viaje y la forma del recorrido desde sus hogares hasta el lugar de encierro (para muchos, conocido porque vivían en las cercanías o trabajaban allí), el movimiento del barco en los días de tormenta (del Buque Ara 9 de Julio), los utensilios en los que les servían la comida (que tenían inscripciones de esa fuerza), etc. Lo mismo cabe con respecto a los del Ejército. Para otros sobrevivientes directamente fue explicitado por las mismas fuerzas que los habían secuestrado. A su vez, localmente circulaba información a través de rumores o de datos aportados por las mismas víctimas.

35 Testimonio de Marta en el marco de la Causa "Fracassi...", T.O.F. N 1 Bahía Blanca, 24 de febrero de 2015.

${ }^{36}$ El informe lo produjo la Prefectura Zona Atlántico Norte (PZAN 57/987 "S" de fecha 26/05/1987), fue citado en los fundamentos de la sentencia por la causa "Fracassi...". Tribunal Oral Subrogante en lo Criminal Federal de Bahía Blanca, óp., cit., 2015, pp. 812-813.

${ }^{37}$ Misiones es una provincia ubicada en el noreste de la Argentina, dentro de la llamada región mesopotámica.

${ }^{38}$ Las leyes de Punto Final y de Obediencia Debida significaron en Bahía Blanca que prácticamente todos los represores quedasen sin ser juzgados, ya que los juicios que se tramitaron en esa ciudad estaban en pleno proceso, sin haber llegado a una sentencia. De hecho, en varias de las entrevistas realizadas con
} 
refleja que pese al temor no se paralizó: adoptó a una niña, algo que considera trascendental para ese momento de su vida; en paralelo, pudo incorporarse a una agrupación teatral, en la que generó vínculos, sintiendo cierta empatía; y varios años después, casi diez, participó, según el informe de inteligencia, en una marcha en contra de la impunidad.

En los otros dos casos también esas sensaciones de vigilancia eran más que un sentir. Silvia por ejemplo, figura en una ficha confeccionada por la DIPBA el día 21 de mayo de 1977, es decir, casi ocho meses después de su secuestro ${ }^{39}$. En el caso de Neli no aparecen estos legajos durante la dictadura, pero sí cuando realizó la inspección ocular en el marco del trabajo de la $\mathrm{CONADEP}^{40}$. De todas maneras, según recuerda, tuvo vigilancia sobre ella y su familia al salir del CCD. Hacia finales del periodo dictatorial, un compañero del colegio de Claudia, su hija mayor, le comentó que vio durante mucho tiempo, luego de que reapareciera, un auto que paraba en la puerta de su casa durante determinadas horas del día con unos hombres que se apostaban afuera. Neli también lo observaba y este comentario corroboraba sus sospechas de que tenía una vigilancia externa. La casa, que debía dar seguridad, ya había sido violentada durante el secuestro y luego de haber salido seguía careciendo de esa condición, lo que generaba en ella la sensación de que no existían sitios seguros.

Pero, además, los testimonios relatan otras maneras de accionar la vigilancia, hubo quienes fueron hostigados por parte de los mismos represores que habían participado de sus procesos de detención y en otros casos, por personal de las fuerzas enviado para amedrentarlos. En el próximo apartado se expondrán algunas de las formas y objetivos de estas intervenciones y cuáles fueron las características que el marco local permitió.

\section{Vigilar y hostigar}

Continuando con la historia de Neli, no sólo tenía esta vigilancia externa, que podría haber sido de alguno de los aparatos de inteligencia, al poco tiempo de salir comenzó a recibir visitas de guardias de la "Escuelita" adentro de su propio domicilio. El primero en ir fue uno apodado "chamamé",41. Durante el testimonio de Claudia en el juicio "Bayón...", el Fiscal Abel Córdoba le preguntó si tuvieron persecuciones luego de liberada, a lo que respondió:

Sí, de una forma muy cruel y extraña, [tuvimos] un visitante por dos años.

Cada tanto venía a mi casa uno de los militares que los cuidaba, les daba

de comer, no sé su nombre, pero le decían "chamamé". Entraba a la casa

sobrevivientes, surgió el recuerdo de que durante los ' 80 fue común cruzarse con el famoso miembro del grupo de tareas 332 de la marina Alfredo Astíz, quien residía en la ciudad.

${ }^{39}$ Ibídem, pp. 714-715.

${ }^{40}$ El trabajo de la delegación local de la CONADEP fue realizado entre mayo y septiembre de 1984, estableciendo un informe propio que fue elevado a la comisión nacional, en el que se presenta, entre otras cosas, un análisis de las características de la represión en la región y un anexo con nombres de víctimas.

${ }^{41} \mathrm{Su}$ verdadero nombre es Felipe Ayala. Fue condenado a prisión perpetua en el juicio por la causa $\mathrm{N}^{\circ} 1067$, caratulada "STRICKER, Carlos Andrés y otros s/privación ilegal de la libertad agravada, reiterada, homicidio agravado reiterado a YOTTI, Gustavo y otros en área controlada oper. Cuerpo Ejército V". 
sin tocar timbre, comía, se sentaba, me decía "cebame unos mates". Él hacía chistes como que era alguien de la familia y todos teníamos que hacer que estábamos bien. ${ }^{42}$

El contexto represivo de finales del '76 y principios del '77, la desarticulación de los espacios de sociabilidad política ${ }^{43}$, sumado a las condiciones subjetivas de Neli, hacían sentir a este personaje, "chamamé", tanta impunidad como para poder hacer este tipo de visitas. Se producía también en el afuera una ostentación de las diferencias en las relaciones de poder entre víctima y victimario, que ahora también involucraba directamente a la familia.

Neli supone que la intención de esta persona al irrumpir en su casa era vigilarla porque ella lo había visto a cara descubierta, era el único guardia que le permitía quitarse la venda de los ojos a la hora de ir al baño ${ }^{44}$. A esto habría que sumar que su desaparición generó solicitadas del sindicato de actores a nivel nacional, por una compañera que pudo escapar hacia Buenos Aires ${ }^{45}$, con lo que quizás también resultó ser una forma de control sobre la posibilidad de que retomara esos contactos, algo que por cierto no hizo.

Por otro lado, hacia finales de diciembre del '76 hubo un secuestro masivo de estudiantes del secundario industrial "Ingeniero César Cipolletti”, ENET N ${ }^{\circ} 1{ }^{46}$, colegio al que concurría Claudia. Ella había participado durante su primer año del centro de estudiantes, con lo que también era posible su persecución. Miembros de un grupo de tareas fueron por ella, pero en la casa no encontraron a nadie. Una vecina les avisó que gente armada la estaba buscando, por eso decidieron que debía ocultarse por un tiempo en la vivienda de un pariente. Sabían de los secuestros de los chicos y del profesor Villalba de la ENET, porque era información que había circulado por compañeros de Claudia ${ }^{47}$.

\footnotetext{
${ }^{42}$ Neli no pudo testimoniar en las audiencias de ese juicio. Viajó hasta Bahía Blanca para hacerlo, pero sufrió un paro cardíaco en los días previos. Si bien quería, le afectó recordar lo sufrido en aquellos años. Testimonio de Claudia en el marco de la Causa "Bayón...", T.O.F. № 1 Bahía Blanca, 28 de marzo de 2012.

${ }^{43}$ Había perdido los contactos con los compañeros del PC.

${ }^{44}$ También pudo observar a Santiago Cruciani, pero en este caso parecería haber sido una situación en la que el represor pretendió intimidarla, ya que antes de liberarla él mismo le pidió que se sacara el "tabique" de los ojos y que viera su rostro. El mirar las caras de los represores podía significar no salir con vida, algo que sabían muchos de los detenidos.

45 Ana María Vidal, Experiencias del “teatro militante” en Bahía Blanca, 1972-1978, Bahía Blanca, Tesis doctoral, UNS, 2016.

46 Se trató de unos doce alumnos y un profesor de la institución, secuestrados entre el 20,21 y 27 de diciembre. Fueron liberados alrededor del 21 de enero.

${ }^{47}$ La historiadora Ana Inés Seitz refleja en un trabajo cómo la información de estos secuestros se esparció en la comunidad bahiense ya en el momento de los hechos, a pesar de no haber sido publicados en los diarios locales y de producirse en el receso escolar de verano. En esto tuvo que ver, según ella, algunas de las características propias del secuestro, por ejemplo: que se produjeron en los hogares de las víctimas, el carácter colectivo (fueron 13 personas), y la pertenencia a una misma institución. Ana Inés Seitz, "Repensando los trabajos de la memoria sobre la última dictadura militar en una escala local. El 'caso de los chicos de la ENET", Jornadas de Investigadores en Formación, IDES, Buenos Aires, 16 y 17 de noviembre de 2011.
} 
Pasados unos días de la navidad, irrumpieron en su hogar "chamamé" y otro de los guardias, al que llamaban "zorzal"48. En esta visita fueron a averiguar sobre Claudia, querían saber dónde estaba, por lo que luego de revisar la casa comenzaron a hacer preguntas sobre ella. Neli respondía que su hija había ido a la Patagonia por el verano y que allá no había teléfono, era la forma con la que trataba de evadirlos, pensando en que no irían.

El hostigamiento no sólo lo accionaban con el interrogatorio. A la vez que los represores intentaban obtener información, lo que ya de por sí generaba terror, le contaban cómo estaban siendo torturados los estudiantes y el profesor secuestrados. Las intenciones de estos represores entonces podrían haber sido la vigilancia sobre Neli y su círculo familiar, pero además había en esas acciones una producción de terror nuevamente sobre la víctima y su círculo cercano. El hecho de amedrentarla con las preguntas sobre su hija y con el relato de las torturas y del destino de otros secuestrados, eran acciones aterrorizantes. Seguían actuando sobre su subjetividad en el afuera.

Visitas de represores, aunque no es extensible a la mayor parte de las historias de los y las sobrevivientes, se dieron también en otras partes del país. Por ejemplo, en Buenos Aires, detenidos que salieron con vida del "Vesubio", del circuito "Atlético-BancoOlimpo" (ABO) o de la Escuela Superior de Mecánica de la Armada (ESMA), debieron padecer este tipo de mecanismo. De hecho, en ABO y ESMA, a pesar de las diferencias en la forma de cómo lo aplicaron, quienes lo padecieron hablan de un régimen de "libertad vigilada"49, en el que debían concurrir a citas o hacer llamados telefónicos donde los represores lo indicaban, cuando no recibir visitas. En Bahía Blanca no parecería haber existido algo llamado de esa manera, no obstante, fueron varios los casos de este tipo de vigilancia y de hostigamiento sobre sobrevivientes y familiares, y como se demuestra en la historia de Neli, el nivel de impunidad con el que actuaron los represores fue clave.

En otros casos de las causas "Bayón..." y "Fracassi...", el accionar intimidatorio en el afuera también aparece. Los siguientes tienen a un represor como protagonista. Claudio y Héctor, que trabajaban en el sector Tesorería de la Municipalidad de Bahía, fueron secuestrados el mismo día, el primero saliendo de su casa y el otro ya en el trabajo. Estuvieron desaparecidos en la "Escuelita" desde el 19 al 24 y 25 de marzo del "76 respectivamente ${ }^{50}$. A los días siguientes de ser liberados, intentaron retomar sus vidas y volvieron a trabajar. En esos momentos, un tal Mario Mancini concurrió a la municipalidad y habló con cada uno por separado. Así relataba Héctor, durante el juicio, esa visita:

Después que me liberaron, un día estaba en la fila para fichar la salida y un compañero me dice que había alguien preguntando si podía verme. En la puerta le pregunté qué quería, me preguntó cómo me encontraba y si lo reconocía. Le dije que bien y que no lo reconocía. "¿Cómo no te acodas

\footnotetext{
${ }^{48} \mathrm{Su}$ verdadero nombre es Arsenio Lavayén. Fue juzgado y condenado a prisión perpetua, en el tercer tramo de los juicios por V Cuerpo, Causa "González Chipont, Julio Guillermo y otros s/privación ilegal de libertad...".

${ }^{49}$ A diferencia de la "libertad vigilada" de los detenidos en cárceles, en estos casos la lógica continuó siendo clandestina, participando en las acciones los propios represores del CCD.

${ }^{50}$ Ambos tenían militancia gremial como empleados municipales.
} 
de mí, macho?", soltó el tipo. Todo el mundo lo conoce como "tío", a lo sumo Mario Mancini, o el nombre verdadero, Santiago Cruciani. Pero [Claudio] y yo lo identificamos como "Macho" porque estaba todo el tiempo diciendo eso. Me preguntó si quería tomar un café y le dije que $\mathrm{no}^{51}$.

La visita era intimidatoria. Quien comandaba la tortura exponía nuevamente su voz $^{52}$, sus códigos, ahora dándole un rostro para que lo reconocieran, como lo hizo también con Neli. Iba al trabajo de Héctor, la municipalidad, donde lo podían ver otros compañeros. Eso pareciera que no importaba, y quizás era la idea que pretendía transmitir, que el poder que tenía en el CCD como para ser uno de los que comandaba la tortura también lo tenía afuera, que podía mostrarse con ese grado de impunidad. En este contexto, tuvo que ir declarar a la comisaría por su desaparición, ya que sus allegados habían hecho la denuncia, allí dejó asentado que no había sido torturado. En su testimonio durante el juicio aclaró que en ese momento no dijo nada por protección y que el temor lo llevó consigo durante mucho tiempo, que fueron tiempos oscuros hasta el retorno de la democracia 53 . Otra "marca" que podría estar relacionada con esta persecución es que en los meses siguientes cambió de lugar de trabajo, dedicándose a la actividad bancaria.

El diálogo con Claudio fue un tanto distinto. Estando allí, Cruciani justificó la tortura, le dijo que no había sido tan grave, que, si tendría que calificarla, de 10 puntos le habría puesto un 5. Por otro lado, le ofreció ser "buchón", algo a lo que Claudio se negó. Eran los primeros días luego del golpe de Estado, con lo que además del amedrentamiento, la búsqueda de un informante podía ser con fines utilitarios, pero también algo humillante, una forma más de continuar afectando su subjetividad.

Durante más de un año Cruciani continuó con el acoso y las amenazas sobre Claudio y su familia, realizando esporádicos llamados telefónicos ${ }^{54}$ y convocándolo a dos entrevistas a las oficinas del Destacamento de Inteligencia 181 del Ejército en la calle Chiclana al 300, centro de la ciudad. El hecho de convocarlo allí, a metros de la municipalidad (también lo había visto entrar en ese lugar Héctor), fue otra forma de teatralizar su poder.

Por la persecución y el hostigamiento, también recibido por parte de los interventores municipales que pertenecían a la Armada, Claudio pidió licencia en el trabajo, como si no quisiera circular por la cotidianidad en la que podría ser acechado. Al enterarse, Cruciani lo llamó pidiendo su reincorporación, diciéndole que no tuviera miedo. En este contexto de intimidación pareciera sugerente el hecho de que se "preocupara" porque aquel regresara a trabajar, porque no tuviera temor. Sin embargo, como se verá en la próxima

\footnotetext{
51 Testimonio de Héctor, brindado en el marco de la "Causa Bayón...", T.O.F. N 1 Bahía Blanca, 27 de septiembre de 2011.

52 En la mayor parte de los testimonios conocidos sobre la "Escuelita", observable también en la causa "Bayón...", los sobrevivientes han referido a la voz particular de uno de las personas que comandaban la tortura. Éste personaje con voz grave era Cruciani.

${ }^{53}$ Fm de la calle, "Nada es igual que antes", Bahía Blanca, Fm de la Calle, 29 de septiembre de 2011. https://juiciobahiablanca.wordpress.com/2011/11/29/nada-es-igual-que-antes/

${ }^{54}$ Los llamados telefónicos fueron otra forma de hostigamiento sobre los sobrevivientes y sus familias.
} 
historia, fue uno de los "roles" que actuó en sus prácticas represivas. Quizás, en este pedido pretendía la reincorporación para continuar ejerciendo un control desde la cercanía que tenían entre sí la municipalidad y las oficinas de la calle Chiclana.

La última visita se produjo a fines del '77, más de un año después de su secuestro, Claudio se estaba dedicando a vender libros, Cruciani le compró uno y le dijo que se iba a una agregaduría militar. En eso no mintió, continuaría con sus "servicios" en la Embajada Argentina en Perú. Por su parte, la víctima dejó finalmente su trabajo y decidió ir a vivir a Lomas de Zamora, como forma de protección. En esta ciudad trabajó como mozo en una parrilla para subsistir, sin hacer mención a nadie sobre lo que le tocó vivir en Bahía Blanca $^{55}$.

Santiago Cruciani fue un hombre de inteligencia del Ejército. Llegó trasladado desde Mendoza al Destacamento de Inteligencia 181 el 12 de febrero del '75. Enseguida se vinculó a la CNU y la triple A local. En los últimos dos meses de ese año viajó a Tucumán para participar en el "Operativo Independencia", volviendo a Bahía Blanca durante los días previos al golpe, ya como uno de los responsables de la tortura en la "Escuelita"56. Sus acciones en la represión también se ejecutaron, como se viene exponiendo, afuera del CCD, intimidando y hostigando a sobrevivientes y familiares. No fueron sólo los casos recién mencionados, con su falsa identidad se infiltró a mediados del ' 76 en la parroquia Nuestra Señora del Carmen como un suboficial del Ejército, comunidad en la que participaban varias personas que desaparecerían durante los últimos meses del año. Además, como también se dijo, trabajó en las oficinas del Destacamento de Inteligencia, en el centro de la ciudad. Puede decirse que era una persona visible en su "invisibiliad" como infiltrado y/o como torturador. Este tipo de circulación en la sociedad era intimidante, porque para aquellos que conocían su importante rol en la represión exponía la impunidad que gozaba al actuar, algo que también se vio en las visitas que padecieron Neli y su familia.

Según las periodistas Lewin y Wormat $^{57}$, para infiltrarse en la comunidad eclesiástica, Cruciani habría generado una relación con una secuestrada, Mercedes, que era vicedirectora del colegio parroquial "Nuestra Señora de la Paz" y que también trabajaba en la municipalidad ${ }^{58}$. Durante los días en los que estuvo secuestrada, el "tío" había actuado como su "protector", impidiendo que la torturaran con la picana y sugiriendo su liberación. Luego de liberarla, comenzó a llamarla por teléfono y a tramar visitas y encuentros, intentando generar un vínculo afectivo. Era el hombre de la voz gruesa que la había "protegido" de la tortura, que tuvo que ver con su "liberación", y que ahora se comunicaba para devolverle los libros que le habían robado durante el secuestro. Estaba interesado en que estuviera bien, le recomendaba inclusive que volviera a trabajar al colegio parroquial y

\footnotetext{
55 Testimonio de Claudio, brindado en el marco de la "Causa Bayón...”, T.O.F. № 1 Bahía Blanca, 06 de septiembre de 2011.

${ }^{56}$ Diego Martínez, "Detuvieron al interrogador del centro clandestino La Escuelita”, Buenos Aires, Página/12, 15 de julio de 2006.

${ }^{57}$ Miriam Lewin y Olga Wormat, Putas y Guerrilleras: crímenes sexuales en los campos de concentración. La perversión de los represores y la controversia en la militancia. Las historias silenciadas. El debate pendiente, Buenos Aires, Planeta, 2014, pp. 417-418.

${ }_{58}$ Mercedes era trabajadora social en la Municipalidad de Bahía Blanca. Fue secuestrada el 21 de marzo de 1976, sometida a interrogatorios en la Escuelita y liberada al día siguiente.
} 
al municipio, que siguiera con su vida normal, que él la acompañaría para que nada le ocurriese y que hablaría con el arzobispo de Bahía Blanca monseñor Mayer ${ }^{59}$. Ella, según testimonió en el juicio, encontró en esta persona protección en un contexto en el que estaba aterrorizada, en el que no quería salir a la calle. Así fue que comenzaron una relación que duró un poco más de un año y de la cual nació una hija. Mercedes sabía que Mario Mancini estaba en inteligencia del Ejército, porque la llamaba desde las oficinas, pero ella no preguntaba más, no quería saber, le daba miedo. Cuando a principios del ' 78 el represor se fue hacia Lima a la agregaduría militar, Mercedes intentó enviarle cartas y todas volvían porque no existía Mancini. A través de un pariente, que pertenecía a la Marina, pudo saber que se trataba de Santiago Cruciani y que éste tenía hijos y una esposa en Mar del Plata.

La hipótesis de las periodistas Lewin y Wormat parecería acertada. Hay en este caso una utilización de la relación con Mercedes para infiltrarse. Desde ese lugar participó en la comunidad de la parroquia, se mostraba con ella. Pero no sólo eso, además de la búsqueda de información (y del nivel de perversión), también se puede observar en sus prácticas una exposición de poder para el afuera, dirigida a aquellos que sabían de sus conexiones con el aparato represor.

Si bien no muchos tenían información de la verdadera identidad, aquellos que sí sabían podían sentirse en peligro. Perla, era en aquellos tiempos la compañera de vida de Julio $^{60}$, miembro de Cáritas, participante en la comunidad eclesiástica de la parroquia Nuestra Señora del Carmen, a cargo del padre Navarro. Recibió una visita intimidatoria de Cruciani a los días de la desaparición de su marido. El represor advirtió que no lo buscara, que no hiciera gestiones, que lo tenía él y que sabía de las actividades de ambos. "A Cruciani lo conocí en mi casa el día 21 de octubre de 1976 dos días después del secuestro de mi marido. Vino a decirme lo que se sabía de mí, que a Julio lo tenía él y que no intentara buscarlo o hacer Hábeas Corpus..." ${ }^{61}$. Desde ese momento dejó de ir a la parroquia, podía poner en riesgo su vida y también la de Julio. Esa exposición de poder generó la ruptura parcial de vínculos sociales muy importantes para ella.

Entonces, hay varias cuestiones que tienen en común las historias presentadas. Por un lado, estos represores continuaron con la búsqueda de información para la detención de más personas a través de los interrogatorios y pedidos de delación, lo que se pudo observar

\footnotetext{
${ }^{59}$ Monseñor Jorge Meyer fue uno de los referentes de la Iglesia Católica durante esos años en Bahía Blanca. Muchos de los testimonios de familiares hablan de que, al pedirle ayuda en la averiguación de los paraderos de los desaparecidos, la frase con la que respondía era que "en algo andarían”, criminalizándolos y negándose de esa manera a dar información. También, algunas de las víctimas han referido verlo dentro del Batallón 181 y en la cárcel, por ejemplo, confesando a los detenidos. Tribunal Oral Subrogante en lo Criminal Federal de Bahía Blanca, óp., cit., 2012.

${ }^{60}$ Julio, comenzó a militar en el Peronismo de Base a fines de los '60. Estuvo desaparecido desde 19 de octubre al 22 de noviembre de 1976 en la Escuelita, siendo luego blanqueado, pasando por los penales U4 de Villa Floresta, la U6 de Rawson y la U9 de La Plata, hasta el 20 de junio de 1981.

${ }^{61}$ Fm de la Calle, "Cruciani era uno más de la comunidad", Bahía Blanca, Fm de la Calle, 25 de octubre de 2011. https://juiciobahiablanca.wordpress.com/2011/10/25/cruciani-era-uno-mas-en-la-comunidad/, ver los "comentarios". Perla también fue objeto de inteligencia por Prefectura. En los alegatos de la Unidad Fiscal, presentaron esa documentación: "La persecución a BARNES, esposa de Julio RUIZ, está asentada en el memorando '79 de la Prefectura de Zona de Atlántico Norte que informa sobre la actividad de la esposa del 'terrorista' Julio RUIZ'.
} 
en las historias de Neli, de los trabajadores de la municipalidad y en la relación establecida de Cruciani con Mercedes. Por otro lado, a diferencia de otras formas de inteligencia, en este tipo de accionar se expusieron intencionalmente. Al hacerlo, en los límites de la "clandestinidad", teatralizaron su poder y la impunidad con la que actuaban. La reaparición misma del aparato represor fue amenazante y en un contexto de afecciones, de rupturas vinculares y de desconfianza, estas prácticas resultaron aterrorizantes. De este modo, el hostigamiento puede ser pensado como un continuum con un proceso más amplio de ataque a las subjetividades iniciado en los CCD.

De todas maneras, si bien estas acciones tuvieron consecuencias en las víctimas, no implicó pasividad por parte de ellas. Al contrario, en casi todos los casos hubo reacciones: Nely, escondió a su hija Claudia cuando tuvo información de que podían secuestrarla; Claudio se negó a ser informante y cambió de trabajo y de ciudad para salir de la cotidianidad donde podía ser vigilado; lo mismo que Héctor, que renunció al municipio y comenzó a trabajar en un banco.

\section{Des-estabilidad}

Para aquellos que padecieron largos periodos de detenciones, semanas o meses en el CCD o tiempos mayores cuando fueron legalizados, el encontrar un trabajo no fue tarea sencilla. En primer lugar, porque para algunos resultó difícil rearmarse en lo subjetivo como para retomar una cotidianidad en lo laboral. Para otros, las complicaciones fueron los largos periodos de ausencia por la desaparición, que pudieron derivar en cesantías ${ }^{62}$. Por ejemplo, de los cincuenta casos de la causa "Fracassi...", diecinueve quedaron cesanteados (en general con una orden de la Armada), lo que indica un número importante. Muchos de ellos eran trabajadores ligados a espacios, empresas e instituciones estatales intervenidas por las FFAA. En el caso de los sobrevivientes legalizados, tuvieron efectos los antecedentes penales. Pero, por si fuera poco, en algunos testimonios también es mencionado un hostigamiento del aparato represor para dificultarles la estabilidad económica. Se expondrán dos casos (no son los únicos) para ejemplificarlo.

En la historia de Patricia se pueden observar muchas de estas cuestiones que se acaban de mencionar, con la excepción de los antecedentes penales ya que no fue legalizada. Esta sobreviviente participaba, junto a su compañero Horacio, en agrupaciones ligadas a la Iglesia Católica. En el año "74 comenzaron a militar en la JP. Fueron secuestrados el 01 de octubre del "76 por la Armada y llevados al CCD "Baterías", estando ella embarazada. Horacio aún permanece desaparecido, mientras que Patricia fue liberada en una ruta cerca del pueblo San Cayetano, luego de cuarenta y siete días. Como en muchos de los casos fue amenazada antes de salir, uno de los personajes del CCD le dijo que iba a volver a ese lugar si continuaba con su militancia en los barrios. Regresó a su casa con

\footnotetext{
${ }^{62}$ Las cesantías acusaban "abandono de trabajo", pero también hubo en muchos de los casos acusaciones por "activismo de izquierda", "comunista" o "subversivo", y "razones de servicio" y de "seguridad". Las leyes 21.260 y la 21.274, promulgadas en los primeros días del golpe de Estado, posibilitaban la baja a personal de planta, transitorio, o contratado, de espacios de la administración pública nacional y de empresas estatales
} 
mucho miedo, sumamente afectada, por eso decidió ir a transitar el embarazo a la casa de su suegra, allí encontró contención:

Yo no podía ir sola al baño, en la casa de mi suegra me acompañaban a ir al baño, mi cuñada, mi suegra, me acompañaban a la vereda, me acompañaban al trabajo y me iban a buscar (...), no pude nunca más durante mucho tiempo salir sola a la calle, ni ir sola al baño, dormía con Lucía, mi cuñada, en la misma cama, porque tenía miedo de dormir sola en la noche ${ }^{63}$.

Pese a este estado anímico, a los días de salir del CCD concurrió a su trabajo, siempre acompañada, en el Registro Civil de Bahía Blanca. Al mes de retomar, por haber tenido más de cuarenta inasistencias injustificadas y por no poder probar su desaparición (a pesar de los testimonios de sus familiares), le hicieron un sumario y la exoneraron. A los meses, luego de nacer Matías, pudo conseguir un empleo como docente en una escuela de General Cerri, un pueblo cercano, en un barrio de condiciones precarias. No obstante, allí también le hicieron saber que no debía continuar, aunque de otra forma:

Yo recuerdo que empecé a trabajar como suplente en una escuela en General Cerri, tenía que acercarme a la casa de los pobres porque los chicos no iban a la escuela, habré trabajado un mes en la escuela, cuando un tío mío, hermano de mi papá, se contacta con un primo de mi papá que tenía relación con la Marina. Ese primo le dice a mi tío que me diga que me estaban siguiendo, y que sabía que si seguía trabajando en ese lugar me volverían a buscar y me matarían, por lo tanto, el trabajo que había conseguido también lo tuve que dejar.

La amenaza en este caso no llegó en forma directa del represor sobre la víctima, sino como un aviso desde familiares ligados a la Armada, no obstante, tuvo un efecto desestabilizador. Para una persona desestructurada de esa manera, a pesar de tener la contención de su familia y amigos, el saberse vigilada y la posibilidad de volver a ser secuestrada generó que abandonara su trabajo ${ }^{64}$.

\footnotetext{
63 Testimonio de Patricia, brindado en el marco de la "Causa Fracassi...", T.O.F. N 1 Bahía Blanca, 25 de noviembre de 2014.

${ }^{64}$ Durante los meses de embarazo también vivió situaciones de tensión con Mario Mancini. Luego de salir comenzó a ir a la Iglesia donde éste estaba infiltrado, antes iba a otra en la que también Navarro daba misa. Allí lo conoció. Recuerda al represor tocándole la panza diciéndole que Matías nacería bien. Durante ese tiempo se fue enterando de las noticias que Mancini le daba a Navarro sobre la situación de personas cercanas. Sobre Horacio, dice que supo que, en abril, un día antes de nacer el hijo de ambos, el infiltrado le dijo al párroco que no había más nada que hacer por él, dándolo por muerto. De todas maneras, Patricia continuó haciendo gestiones junto a otros familiares, como por ejemplo yendo a ver al Obispo Jaime De Nevares a Neuquén. En otra anécdota recuerda que un día, esperando el colectivo, pararon Mancini y Mercedes, la hicieron subir al auto y el represor le preguntó: “(...) ‘ ¿vos sabes que a vos te tuvo la Marina?' Y me preguntó: ‘¿cómo se decían entre ellos?’. Yo le dije, 'Laucha, Viejo...'. Entonces la miró a su pareja y le dijo: 'qué hijos de puta, utilizan los mismos sobrenombres que el Ejército"”.
} 
En otras historias, el hostigamiento fue directo. Oscar, que había militado en el Peronismo de Base, luego de pasar por el CCD la Escuelita y por la Unidad $\mathrm{N}^{\mathbf{0}} 4$ y el penal $N^{o} 6$ de Rawson, salió en libertad en diciembre del ' $78^{65}$. Relata que le costó mucho conseguir un trabajo estable, que lo que podía conseguir era precario y siempre de la mano de algún conocido. Realizó changas, pero no alcanzaban para reacomodarse. Esta fue una característica que se extiende a sobrevivientes que fueron "blanqueados" también en otras zonas del país, la estigmatización de haber estado preso al momento de conseguir trabajo y la necesidad de la solidaridad de gestos de gente conocida para afrontarlo ${ }^{66}$. Los antecedentes penales eran una carga, pero también debe sumarse como factor la presión que represores realizaron para dificultarles este aspecto. Cuando pudo por fin conseguir algo en una empresa de ventas de agroquímicos de un conocido, a los días le dijo, con lágrimas en los ojos, que no iba a poder ser, éste había recibido amenazas para que no lo tomara. "Me avisaron que...Me dijeron que no te tome...'. No me quiso dar ningún detalle de quiénes". "Yo estaba en listas, fui a varios lados, pero no había chances, la única que quedaba era el cuentapropismo". De esta manera, continuaba bajo vigilancia luego de haber salido del proceso de detenciones.

El objetivo podría haber sido que Oscar no se insertara en una empresa en la que conviviría cotidianamente con otros trabajadores, incidir en la posibilidad de que generara lazos, por lo menos tempranamente; pero también una forma más de amedrentamiento, de hacerle sentir la presencia del aparato represor en su vida, de mostrarse, actuando sobre su subjetividad. A estas acciones deben sumarse llamados intimidatorios, seguimientos, y las amenazas que recibió su compañera por parte de alguien que decía ser de inteligencia ${ }^{67}$, prácticas también de hostigamiento y desestructuración. Todas estas situaciones de persecución llevaron a que a fines del '79 tomaran la decisión de partir hacia el exilio en México, donde estuvieron en un contexto menos hostil. Allí encontraron, gracias a la solidaridad de compañeros, un techo, un trabajo, contención y escucha ${ }^{68}$.

\footnotetext{
${ }^{65}$ Entrevista personal con Oscar, Buenos Aires, 25 de enero de 2016. Oscar fue militante del Peronismo de Base desde fines de los años '60. Trabajó como no docente en la Universidad Nacional del Sur desde el ' 72 , participando en los gremios ADUNS y FATU. En el ' 75 tuvo que huir de Bahía Blanca hacia Viedma, con su compañera e hijas, al ser perseguido y amenazado de muerte por las fuerzas paraestatales de la triple A local, estando intervenida la universidad por Remus Tetu, un rector ligado a ellas. Fue secuestrado en la ciudad rionegrina el 07 de enero de 1977 por miembros de la PFA y llevado al CCD la "Escuelita". Lo legalizaron once días después en la cárcel de Villa Floresta, siendo trasladado a los meses a Rawson, donde recuperó su libertad en diciembre del ' 78 .

${ }^{66}$ Rama, óp., cit., p. 74.

${ }^{67}$ A la compañera de Oscar la habían echado del trabajo estando embarazada, con lo que quiso comenzar un juicio laboral a la empresa, la editorial La Ley. Al poco tiempo de iniciarlo tuvo que enfrentarse con personal de las fuerzas que fueron a intimidarla. Durante el testimonio que brindó María Noemí en el juicio, detalló esa escena. Equipo Nikzor, Sinopsis de la audiencia de 29 nov. 11 en el juicio por crímenes contra la humanidad cometidos bajo control operacional del Comando V Cuerpo de Ejército con sede en Bahía Blanca, Comando $V$ Cpo de Ejército, Bahía Blanca, audiencia del martes 29 de noviembre de 2011. http://www.derechos.org/nizkor/arg/doc/bbca105.html
}

${ }^{68}$ Entrevista personal con Oscar, Buenos Aires, 25 de enero de 2016. 


\section{Reflexiones finales}

Las prácticas de vigilancia sobre los sobrevivientes, entonces, deben insertarse en una temporalidad más amplia del ejercicio de la inteligencia sobre organizaciones y determinadas personas de la población, que tuvo continuidades tanto en etapas democráticas como en dictaduras. Los registros durante la etapa analizada exponen, entre otras formas: seguimientos; pedidos de antecedentes; controles telefónicos; las entradas y salidas de los espacios de encierro "legales" y las visitas allí recibidas; las opciones o expulsiones del país; las cesantías laborales; denuncias en comisarías u otras instituciones; y la participación en agrupaciones políticas, gremiales o culturales. Basándonos en las causas "Bayón..." y "Fracassi...", los que padecieron actividades por parte de los servicios de inteligencia luego de salir de los CCD representan más de un $74 \%$ de la totalidad de sobrevivientes que fueron casos, lo que es un porcentaje considerable. A este cálculo hay que sumar las experiencias de aquellos que la tuvieron y que no aparecen en los partes que fueron utilizados como prueba en los juicios. En este sentido al momento, se han conocido sólo las fichas o información de inteligencia que estaban almacenadas en los archivos de la ex DIPBA y del SIPNA, siendo que la comunidad informativa agrupaba a varios servicios más, incluyendo al del Ejército y al de la Armada, ambos, clave en su funcionamiento.

En un principio, sobre todo al tiempo de haber sido liberados, fue común para los sobrevivientes sentirse vigilados: luces de autos que los seguían, frenadas, personas apostadas cerca de sitios donde circulaban. Esas percepciones deben ser incluidas en un contexto más amplio de desestructuración y de manifestación de los efectos psicosociales de la represión. La manera de procesarlo dependió de la persona, de sus experiencias represivas previas, de cuán afectada estaba su subjetividad, sobre todo por la experiencia del CCD y por el grado de rupturas en sus vínculos. Para algunos fue algo que no tuvo demasiada influencia, en cambio en otros generó miedos que perduraron durante muchos años.

Es necesario también pensar en las reconstrucciones que realizaron las propias víctimas con respecto de lo que les sucedió, desde las que pudieron tener indicios o certezas de la actuación de las fuerzas en sus secuestros. En este sentido, el saberse conviviendo en la sociedad con miembros de las instituciones que tuvieron que ver con esas afecciones produjo consecuencias.

Por otro lado, además de la vigilancia, hubo sobre ciertas personas un accionar de hostigamiento. Las modalidades variaron: visitas a los sobrevivientes en sus casas, en sus trabajos o en la cotidianidad en un nivel más general; los llamados telefónicos amenazantes o en los que buscaron generar algún otro tipo de vínculo; los seguimientos; y la desestabilización en lo económico. Algunos de los testimonios revelaron que los represores pretendieron obtener información para seguir produciendo detenciones, sobre todo durante los años '76 y '77. Pero también, lo que tienen en común estas acciones es que hay una intención de continuar afectando la subjetividad de la víctima y a su círculo íntimo, ya fuera desde prácticas aterrorizantes o actuando sobre cuestiones fundamentales de la vida cotidiana, como por ejemplo en lo laboral. Entendiendo que los espacios de encierro, tanto 
los CCD como las cárceles ${ }^{69}$ fueron dispositivos que tuvieron como uno de sus objetivos afectar la subjetividad de los recluidos, se puede pensar, en este sentido, en continuidades con respecto a los que sobrevivieron a esas experiencias.

En los años analizados, del '76 al '79, las historias narradas que señalan estas prácticas de hostigamiento muestran el grado de impunidad con el que actuaban los miembros de las fuerzas. Sin salir de una lógica clandestina, el represor se mostraba afuera, donde podía ser visto por los otros, por la familia, por compañeros de trabajo, por amigos. Circulaba por la ciudad, era parte de la sociedad, como el caso de Santiago Cruciani, que tenía sus oficinas en el centro, que mantenía una relación con una sobreviviente y que además estaba infiltrado en la comunidad de la parroquia. De esta manera, a diferencia de la vigilancia que aparece en los registros de los servicios de inteligencia, en estas acciones de hostigamiento hubo intenciones de relativa visibilidad, ya que esta podía ser coercitiva.

Este accionar de los represores en el afuera tuvo distintos efectos en cada una de las víctimas. Al igual que con las "sensaciones de vigilancia", la forma de abordarlo dependió del estado en el que se encontraba el propio sobreviviente, de su subjetividad, como así también de los lazos que pudo (re)establecer durante la re-vinculación. En general, en los casos presentados pareciera ser un elemento más, aunque de importancia, en la desarticulación y desestructuración de la víctima. De todas maneras, como se vio, también hubo márgenes para actuar, el miedo no siempre significó pasividad.

\section{Bibliografía}

Munu Actis, Cristina Aldini, Liliana Gardella, Miriam Lewin, Elisa Tokar, Ese infierno: Conversaciones de cinco mujeres sobrevivientes de la ESMA, Buenos Aires, Sudamericana, 2001.

Pilar Calveiro, Poder y desaparición: Los campos de concentración en Argentina, Buenos Aires, Ed. Colihue, 2008 [1998].

Débora D'Antonio, La prisión en los '70: Historia, género y política. Buenos Aires, Biblos, 2017.

Débora D’Antonio, "Vigilancia, control social y agencia política del activismo por los derechos humanos ante la llegada de la Comisión Interamericana de Derechos Humanos (Argentina, 1979)", Izquierdas, 32, marzo 2017: 184-202.

Eduardo Luis Duhalde, El Estado Terrorista argentino: 15 años después, Buenos Aires, Eudeba, 1999.

Daniel Feierstein, El genocidio como práctica social: entre el nazismo y la experiencia argentina, Buenos Aires, Fondo de Cultura Económica, 2007.

Marina Franco, "Pensar la violencia estatal en la Argentina del siglo XX", Buenos Aires, Lucha Armada en la Argentina, Año 8, Anuario 2012, pp. 20-31.

${ }^{69}$ Débora D’Antonio, La prisión en los '70: Historia, género y política, Buenos Aires, Biblos, 2017. 
Patricia Funes, "Medio siglo de represión. El Archivo de la Dirección de Inteligencia de la Policía de la Provincia de Buenos Aires”. La Plata, Revista Puentes (11), 2004.

Silvina Jensen, Diálogos entre la Historia Local y la Historia Reciente en Argentina. Bahía Blanca durante la última dictadura militar, Rey Tristán, Eduardo; Calvo González, Patricia, XIV Encuentro de Latinoamericanistas Españoles: congreso internacional, Sep. 2010, Santiago de Compostela, Spain, Universidad de Santiago de Compostela, Centro Interdisciplinario de Estudios Americanistas Gumersindo Busto; Consejo Español de Estudios Iberoamericanos, pp.1426-1447, Cursos e Congresos; 196.

Emmanuel Nicolás Kahan, “QQué represión, qué memoria? El archivo de la represión de la DIPBA: Problemas y perspectivas", Question, vol. № 1, No. 16, 2010, 1-10. http://perio.unlp.edu.ar/ojs/index.php/question/article/view/459

Diana Kordon, Lucila Edelman, Darío Lagos, Raquel Bozzolo, Elena Nicoletti, Daniela Siaky, Ester Kandel, Marta Hoste, Osvaldo Bonano, Daniel Kersner, Efectos psicológicos de la represión política, Buenos Aires, Sudamericana, 1986.

Julieta Lampasona, "Desaparición forzada en Argentina: entre la desaparición y la sobrevida. O sobre la 'regla' y la 'excepción' en el despliegue de la tecnología de poder genocida", La Plata, Aletheia, volumen 3, número 6, julio 2013.

María Lorena Montero, "El rol de la 'comunidad informativa' en la represión en Bahía Blanca (1975-1977): prácticas, acuerdos y disputas”, en Gabriela Águila, Gabriela, Santiago Garaño y Pablo Scatizza (coordinadores), Represión estatal y violencia paraestatal en la historia reciente argentina: Nuevos abordajes a 40 años del golpe de Estado, La Plata: Universidad Nacional de La Plata. Facultad de Humanidades y Ciencias de la Educación, 2016.

Miriam Lewin y Olga Wormat, Putas y Guerrilleras: crimenes sexuales en los campos de concentración. La perversión de los represores y la controversia en la militancia. Las historias silenciadas. El debate pendiente, Buenos Aires, Planeta, 2014.

Cristian Rama, Sobreviviendo: Experiencias en el marco del proceso de aparición de sobrevivientes de los centros clandestinos de detención de la última dictadura militar (Tesis de Licenciatura en Historia Buenos Aires), FFyL, UBA, 2015.

Ana Inés Seitz, "Repensando los trabajos de la memoria sobre la última dictadura militar en una escala local. El 'caso de los chicos de la ENET'”, Jornadas de Investigadores en Formación, IDES, Buenos Aires, 16 y 17 de noviembre de 2011.

Ana María Vidal, Experiencias del "teatro militante” en Bahía Blanca, 1972-1978, Bahía Blanca, Tesis doctoral, UNS, 2016.

Mario Villani, Fernando Reati, Desaparecido: Memorias de un cautiverio, Buenos Aires, Biblos, 2011.

Jorge Federico Watts, Memoria del infierno: Relato testimonial de un sobreviviente del Centro Clandestino El Vesubio, Buenos Aires, Ed. Continental, 2009.

Ana Belén Zapata, Andamios de experiencias: Conflictividad obrera, vigilancia y represión en Argentina. Bahía Blanca, 1966-1976, Tesis de posgrado, Universidad Nacional de La Plata. Facultad de Humanidades y Ciencias de la Educación, 2014. 
Ana Belén Zapata, Como el herrero que machaca sobre el yunque hasta moldear la forma ideal. La Nueva Provincia y su construcción del llamado “delincuente subversivo” (1975-1977), en Rehime, dossier 07, La prensa periódica provincial durante la última dictadura militar argentina (1976-1983), 2014.

Ana Belén Zapata, "Perseguidos de larga data: vigilancia y represión en trabajadores ferroviarios. Bahía Blanca (1958-1976)”, en Patricia Funes (dir.), Revolución, Dictadura y Democracia. Lógicas militantes y militares en la historia reciente de Argentina en América Latina, Buenos Aires, Imago Mundi, 2016, pp.142-163.

Fuentes documentales impresas

Diego Martínez, "Detuvieron al interrogador del centro clandestino La Escuelita". Buenos Aires, Página/12, 15 de julio de 2006.

Diego Martínez, "El primer desaparecido de Bahía", Buenos Aires, Página/12, lunes 25 de marzo de 2013. https://www.pagina12.com.ar/diario/elpais/1-216541-2013-0325.html

Tribunal Oral Subrogante en lo Criminal Federal de Bahía Blanca, Poder Judicial de la Nación. Fundamentos dictados en la causa $N^{\circ} 982$ caratulada "BAYÓN, Juan Manuel y otros s/privación ilegal de la libertad agravada, reiterada, aplicación de tormentos reiterada, homicidio agravado, reiterado a Bombara, Daniel José y otros en área del Cuerpo Ejército V”. Bahía Blanca, 06 de noviembre de 2012. http://www.cij.gov.ar/nota10317-Lesa-humanidad--difunden-fallo-que-conden--en-Bah-a-Blanca-a-14-acusados-aprisi-n-perpetua.html

Tribunal Oral Subrogante en lo Criminal Federal de Bahía Blanca, Poder Judicial de la Nación. Fundamentos dictados en la causa 1.103 caratulada "FRACASSI, Eduardo René y otros por privación ilegal de la libertad agravada, reiterada, aplicación de tormentos reiterada, homicidio agravado reiterado a AGUILAR, Guillermo Aníbal y otros (Armada Argentina)"). Bahía Blanca, 25 de noviembre de 2015. http://www.cij.gov.ar/nota-20136-Lesa-humanidad--difunden-fallo-que-conden--a-los-22acusados-en-un-juicio-oral-en-Bah-a-Blanca.html

Fuentes documentales electrónicas

Unidad Fiscal de Bahía Blanca, Alegato de la Unidad Fiscal en el primer juicio a represores en Bahía Blanca, Bahía Blanca, Agosto de 2012. Transcripto en el Blog Bahía Gris: http://bahiagris. blogspot.com.ar/2012/08/alegato-de-fiscalia-5-contexto-local.html

Equipo Nikzor. Sinopsis de la audiencia de 29 novllen el juicio por crímenes contra la humanidad cometidos bajo control operacional del Comando V Cuerpo de Ejército con sede en Bahía Blanca, Comando V Cpo de Ejército, Bahía Blanca, martes 29 de noviembre de 2011. http://www.derechos.org/nizkor/arg/doc/bbca105.html

Fm de la calle. "Nada es igual que antes", Bahía Blanca, Fm de la Calle, 29 de noviembre de 2011. https://juiciobahiablanca.wordpress.com/2011/11/29/nada-es-igualque-antes/ 
Fm de la Calle, "Cruciani era uno más de la comunidad", Bahía Blanca, Fm de la Calle, 25 de octubre de 2011. https://juiciobahiablanca.wordpress.com/2011/10/25/crucianiera-uno-mas-en-la-comunidad/,

\section{Testimonios orales}

Entrevista personal con Nélida, Buenos Aires, septiembre del 2016.

Entrevista personal con Oscar, Buenos Aires, 25 de enero de 2016.

Entrevista personal con René, Bahía Blanca, 08 de marzo de 2016.

Testimonio de Claudia en el marco de la Causa "Bayón...", T.O.F. No 1 Bahía Blanca, 28 de marzo de 2012.

Testimonio de Claudio en el marco de la Causa "Bayón...", T.O.F. No 1 Bahía Blanca, 06 de septiembre de 20012.

Testimonio de Héctor en el marco de la Causa "Bayón...", T.O.F. N ${ }^{\circ} 1$ Bahía Blanca, 27 de septiembre de 2011.

Testimonio de Patricia en el marco de la Causa "Fracassi...", T.O.F. No 1 Bahía Blanca, 25 de noviembre de 2014.

Testimonio de Silvia en el marco de la Causa "Fracassi...", T.O.F. N ${ }^{o} 1$ Bahía Blanca, 09 de diciembre de 2014. 